\title{
The clinical significance of MIA gene in tumorigenesis of lung cancer
}

\author{
Q.H. GU, D. LI, Z.H. XIE, Q. B. SHEN* \\ Department of Cardio-Thoracic Surgery, Huzhou Central Hospital, Huzhou, China \\ ${ }^{*}$ Correspondence: sqb0046@126.com
}

Received May 11, 2019 / Accepted September 11, 2019

\begin{abstract}
Lung cancer is a common malignant disease in humans. Both the incidence rate and death rate keep growing in recent years and the prognosis of lung cancer patients is disappointing. Melanoma inhibitory activity (MIA) is a secreted protein and a serum marker for metastasis of melanoma. MIA was reported as an oncogene in several cancers. But its role in lung cancer was unknown. In this study, MIA level was shown to be increased in peripheral blood of 216 patients with lung cancer. And it was expressed much higher in tumor tissues than the normal control. Moreover, MIA expression was associated with the clinical stage of lung cancer. When MIA was knocked down, the viability, migration and invasion of A549 cells were remarkably suppressed. But the cell apoptosis rate was enhanced reversely. In contrast, overexpression of MIA promoted cell proliferation, migration and invasion while cell apoptosis was inhibited. Mechanically, the anti-apoptosis marker Bcl-2 was increased and pro-apoptosis marker Bax was decreased after MIA was overexpressed in A549 cells, and vice versa. The level of PCNA and PI3K/mTOR signaling molecules was also increased when MIA was upregulated but declined after knockdown of MIA. In conclusion, MIA plays an oncogenic role in lung cancer and might be a potential marker for the diagnosis of lung cancer.
\end{abstract}

Key words: MIA, PCNA, Bax, Bcl-2, lung cancer

Despite the advancement in diagnosis and therapy, lung cancer remains the most common cause of cancerrelated deaths worldwide. The latest data demonstrates that the estimated number of new patients with lung cancer is 230,000 , accounting for about $13 \%$ of all new cases in the USA in 2018 [1,2]. The estimated deaths are about 154,000, accounting for about $25 \%$ of all deaths caused by cancer [1, $2]$. What's worse, the prognosis of patients with lung cancer is dismal. The 5 -year survival rate was just $18 \%[1,2]$. And it was only $3 \%$ for those patients diagnosed at a distant stage. Unfortunately, $57 \%$ of patients were firstly diagnosed at a distant stage $[1,2]$. One of the reasons might be the heterogeneity of lung cancer, which results in the inefficiency of current therapies and drugs [3]. Therefore, there is no time left to develop new molecular markers for diagnosis as well as therapy of lung cancer patients.

Lung cancer is heterogeneous cancer [3]. A list of genes has been proved to play critical roles in the development or progression of lung cancer $[4,5]$. Melanoma inhibitory activity (MIA) is a small secreted protein mainly expressed in cartilage and malignant melanoma [6, 7]. MIA was proven as a serological marker for metastatic melanoma patients and inhibited growth or attachment of melanoma cells $[8,9]$. MIA was shown to interact with extracellular matrix components, such as laminin, fibronectin and integrin receptors, such as integrin $\alpha 4 \beta 1, \alpha 5 \beta 1$ and cadherin-7. All these molecules played important roles in the process of cell migration and invasion $[10,11]$. In a study by Schmidt et al., dimerization of MIA was shown to be essential for its function in melanoma, which resulted in the development of target agents against MIA [12]. Besides the role in melanoma, MIA was also shown to be expressed abundantly in neurofibromatosis type 1 [13]. And MIA was reported to be associated with nodal metastasis, lymphangiogenesis and poor prognosis in oral squamous cell carcinoma by regulating the expression of ERK1/2, p38 and VEGF family members [14, 15]. Then in high-grade glioma, the level of MIA was clinically correlated to tumor progression [16]. In gastrointestinal cancers, MIA was detected positively in the serum of patients [17]. Further, MIA was involved in the tumorigenesis of pancreatic, liver, breast, and colorectal cancer [18-21]. In a word, MIA contributed to the formation and/or progression in a series of cancers. But the role of MIA in lung cancer is not known yet.

In this study, we determined the expression level of MIA in the serum as well as in tumor tissues of patients with 
lung cancer. Then we demonstrated that MIA was essential for proliferation, migration, invasion, and apoptosis of lung cancer cells. And western blot analysis suggested that the expression of apoptosis-related and proliferation-related molecules was regulated by MIA.

\section{Materials and methods}

Cell culture and clinical samples. A549 cells were purchased from Cell Bank Type Culture Collection of Chinese Academy of Sciences (CBTCCCAS, China) and cultured in DMEM medium (Gibco, USA) with 10\% FBS at $37^{\circ} \mathrm{C}$ under $5 \% \mathrm{CO}_{2}$ conditions.

A total of 311 lung cancer tissues and the adjacent normal tissues were obtained from the Department of CardioThoracic Surgery in Huzhou Central Hospital, along with the peripheral blood from 214 healthy persons and 216 lung cancer patients. Written informed consent was obtained from each patient. All related experiments were approved by the Ethics Committee of Huzhou Central Hospital.

Transfection of siRNA and plasmid overexpressing MIA. About $2 \mu \mathrm{g}$ of siRNA targeting MIA or plasmid overexpressing MIA was transferred into A549 cells with Lipofectamine $^{\mathrm{TM}} 2000$ transfection reagent (ThermoFisher Scientific, USA) for $4 \mathrm{~h}$. Then the supernatant was replaced with fresh medium and cultured for $24 \mathrm{~h}$ to $48 \mathrm{~h}$ and treated cells were used for each experiment.

Cell viability assay. A total of 5000 A549 cells/well were inoculated into a 96-well plate and cultured in DMEM medium with 10\% FBS (Gibco, USA). After $72 \mathrm{~h}$, about $20 \mu \mathrm{l}$ of MTT agent ( $5 \mathrm{mg} / \mathrm{ml}$, Sigma, USA) was added and cultured for another $4 \mathrm{~h}$. Then the supernatant was replaced with $150 \mu$ l of DMSO (Sigma, USA) and the absorbance values (A) at $490 \mathrm{~nm}$ were measured on a microplate reader and recorded.

Cell migration assay. A total of $3 \times 10^{5}$ cells treated with siMIA or plasmid overexpressing MIA for $24 \mathrm{~h}$ were seeded into the upper chamber $(8.0 \mu \mathrm{m}$ pore size, Millipore, USA) and was inserted into a 24-well plate. In the lower chamber, $600 \mu \mathrm{l}$ of fresh medium containing $20 \%$ FBS was added. Then the cells were cultured for another $24 \mathrm{~h}$ at $37^{\circ} \mathrm{C}$. The cells on the upper part of the membrane were removed and the cells on the downside were stained with Hoechst 3342 dye. Then the cells in ten random fields were observed under a microscope (Olympus, Japan) and the migration rate of A549 cells was calculated.

Transwell assay. The upper chamber $(8.0 \mu \mathrm{m}$ pore size, Millipore, USA) was coated with $100 \mu \mathrm{l}$ Matrigel (BD Biosciences, China) for $30 \mathrm{~min}$ at $37^{\circ} \mathrm{C}$ and was inserted into a 24 -well plate. Then a total of $2 \times 10^{4}$ A549 cells were seeded into the upper chamber and treated with siMIA or plasmid overexpressing MIA for $24 \mathrm{~h}$. In the lower chamber, $600 \mu \mathrm{l}$ of fresh medium containing $20 \%$ FBS was added. Then the cells were cultured for another $24 \mathrm{~h}$ at $37^{\circ} \mathrm{C}$. The cells on the upside were removed and the cells on the downside were stained with Hoechst 3342 dye. Then the cells in ten random fields were observed under a microscope (Olympus, Japan) and the invasion rate of A549 cells was calculated.

Apoptosis analysis with Annexin V-FITC/PI. A549 cells treated with siRNA or plasmid overexpressing MIA were seeded into a 6 -well plate and cultured for $48 \mathrm{~h}$ at $37^{\circ} \mathrm{C}$. About $1 \times 10^{6}$ cells were collected and washed with PBS followed by suspending with $100 \mu \mathrm{l}$ Binding buffer. Then $5 \mu \mathrm{l}$ of Annexin V-FITC, $10 \mu \mathrm{l}$ of PI and $5 \mu \mathrm{l}$ of Hoechst 33342 dye were added into the cells and incubated for $10 \mathrm{~min}$ at room temperature. At last, cells were analyzed with fluorescence microscopy (Nikon, Tokyo, Japan).

Immunohistochemistry analysis (IHC). A total of 40 human lung cancer tissues and 10 normal tissues were fixed in $4 \%$ paraformaldehyde and embedded in paraffin. Tumor tissues were sectioned into $5 \mu \mathrm{m}$ and incubated with antibody against MIA (1:300, ab166932, Abcam, NY, USA) for $12 \mathrm{~h}$ followed by incubation with streptavidin-peroxidase complex. Peroxidase conjugates were determined using 3,3'-diaminobenzidine solution.

Western blotting. A549 cells treated with siMIA or plasmid overexpressing MIA were cultured for $48 \mathrm{~h}$ and collected for extraction of total protein. Then the protein was quantified with BCA Protein Assay Kit (Generay, China). About $30 \mu \mathrm{g}$ of total protein were separated and transferred onto a PVDF membrane and incubated overnight with primary antibody against $\beta$-actin (A5441, 1:500, Sigma, USA), Bax (2772, 1:500), Bcl-2 (15071, 1:500), PCNA (2586, 1:500) from Cell Signaling Technology, USA, PI3K (ab138364, 1:300), Akt (ab179463, 1:250), Cyclin D1 (ab226977, 1:200), mTOR (ab109268, 1:250) from Abcam, USA. Then the membrane was incubated with goat anti-rabbit IRDye (926-32211, 1:20000, Odyssey, USA) or goat anti-mouse IRDye (926-32212, 1:20000, Odyssey, USA) for $1 \mathrm{~h}$ at $37^{\circ} \mathrm{C}$. After wash for 3 times with TBST buffer, the membrane was analyzed in an Infrared Imaging System (Odyssey, USA). And the gray value of each band on the PVDF membrane was calculated with Photoshop software.

Statistical analysis. All data were displayed as mean \pm standard deviation and the differences between two groups were analyzed with unpaired t-test or ANOVA on SPSS 11.0 software. A p-value $<0.05$ stands for significant difference.

\section{Results}

MIA expression was increased in patients with lung cancer. MIA was proved to be a serological marker for the diagnosis of metastatic melanoma. Accordingly, we compared the expression level of MIA in peripheral blood of patients with lung cancer and healthy subjects. As shown in Figure 1A, MIA expression in the peripheral blood of 216 lung cancer patients was significantly increased compared to that in 213 healthy controls (1036 \pm 37.19 vs. $898.5 \pm 50.53 \mathrm{pg} / \mathrm{ml}, \mathrm{p}=0.0331$ ). Furthermore, the concentration of MIA in lung cancer tissues was much higher than in 
the healthy group (Figure 1B). The difference between these two groups was statistically significant $(\mathrm{p}=0.0244)$. Then IHC analysis of 40 cases displayed stronger expression of MIA in tumor tissues than the control (Figure 1C). In addition, the clinicopathological analysis showed that MIA expression level was much higher in stage III/IV tissues than in stage I/ II tissues ( $\mathrm{p}=0.036$, Table 1 ). Based on these data, MIA could be considered as a clinical marker for diagnosis or therapy of patients with lung cancer.

MIA was essential to the aggressiveness of lung cancer cells. MIA was reported to regulate cell invasion behavior in melanoma and pancreatic cancer. In this study, we increased the expression of MIA in A549 cells. As a result, the migration ability of A549 cells was enhanced (Figure 2A). But

Table 1. Relationship between MIA expression and clinicopathological features of patients with lung cancer.

\begin{tabular}{lccc}
\hline Group & Cases $(\mathbf{n})$ & $\begin{array}{c}\text { MIA expression } \\
(\mathbf{p g} / \mathbf{m g} \text { total protein })\end{array}$ & $\mathbf{p}$-value \\
\hline Sex & & & 0.073 \\
$\quad$ Male & 25 & $14.12 \pm 1.21$ & \\
$\quad$ Female & 19 & $16.03 \pm 1.21$ & \\
Age & & & 0.125 \\
$\quad$ 660 & 21 & $15.28 \pm 0.98$ & \\
$\quad<60$ & 23 & $13.71 \pm 1.06$ & \\
TNM stage & & & 0.081 \\
T1/T2 & 15 & $20.46 \pm 0.93$ & \\
T3/T4 & 29 & $19.81 \pm 1.93$ & \\
Clinical stage & & & \\
I/II & 14 & $10.01 \pm 0.74$ & \\
III/IV & 30 & $28.08 \pm 1.83$ & \\
\hline
\end{tabular}

knockdown of MIA by specific siRNA suppressed migration of A549 cells (Figure 2B). Consistently, overexpression of MIA promoted invasiveness in A549 cells when knockdown of MIA inhibited invasion of A549 cells by about 20\% (Figures 2C, 2D). Therefore, MIA regulated cell migration and invasion in lung cancer.

MIA contributed to the proliferation of lung cancer cells. To date, the effects of MIA on cell invasiveness have been confirmed in more than one tumor, but its role in tumor cell proliferation was rarely reported. However, unlimited cell expansion is a hallmark in all types of tumors. In this study, the viability of A549 cells was shown to be enhanced by about $40 \%$ after MIA was overexpressed (Figure 3A). In contrast, knockdown of MIA greatly inhibited the cell viability of A549 cells (Figure 3B). These data suggested for the first time that MIA played important roles in the proliferation of lung cancer cells.

MIA suppressed apoptosis in lung cancer. Apoptosis was hazardous to tumor cells. Evading from cell apoptosis was common in tumors. Here, to determine the effect of MIA on apoptosis in lung cancer, fluorescence microscopy with Annexin V-FITC/PI dye was carried out. As seen in Figure 4A, Annexin V-positive cells were remarkably declined after MIA was overexpressed in A549 cells. The apoptosis rate of A549 cells decreased by about $8 \%$ in MIA-overexpressing cells. On the contrary, the knockdown of MIA induced cell apoptosis to nearly $40 \%$ compared to only $20 \%$ in control (Figure $4 \mathrm{~B}$ ). Therefore, MIA suppressed cell apoptosis in lung cancer.

MIA regulated expression of apoptosis- and proliferation-related genes. Based on the above text, MIA was a favorable factor in the progression of lung cancer. But what's the
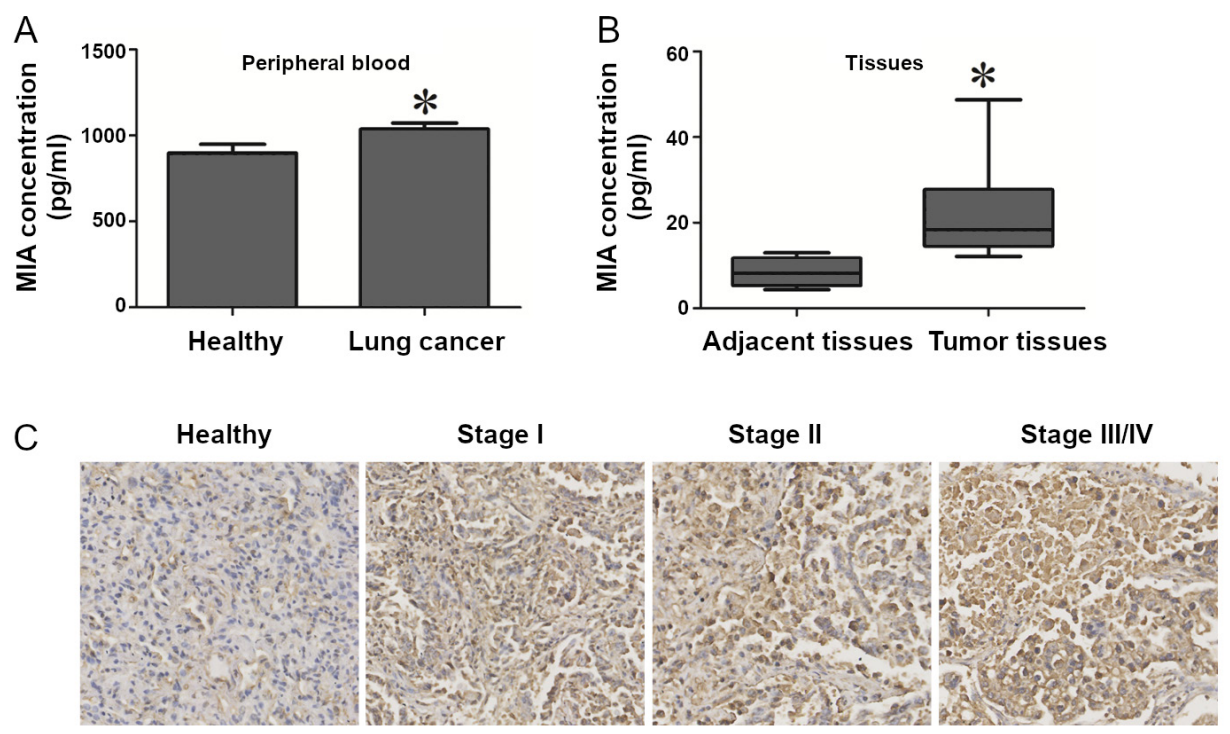

Figure 1. The expression pattern of MIA in lung cancer. A) MIA was expressed significantly higher in peripheral blood from lung cancer patients than healthy persons. B) The protein level of MIA in tumor tissues was much higher than in paired adjacent normal tissues. C) IHC analysis showed the expression of MIA in tissues from healthy control, stage I, stage II, stage III/IV patients with lung cancer. ${ }^{*} p<0.05$ showed significant difference between two groups. 
A

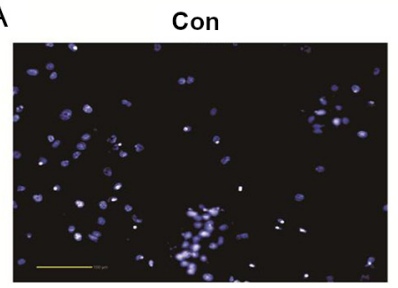

B

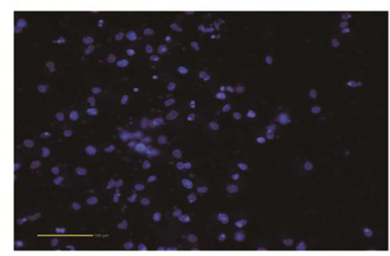

C

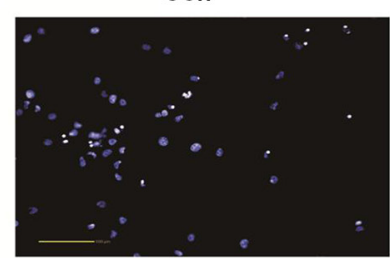

D

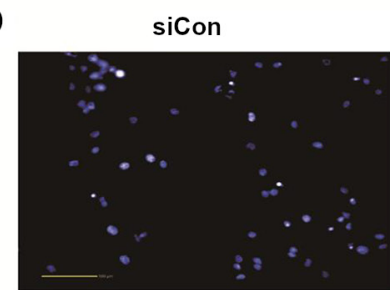

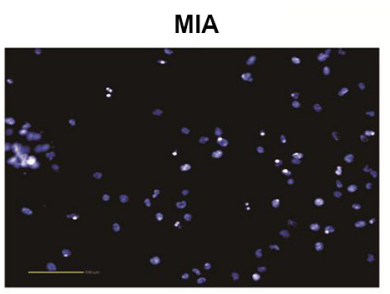

siMIA

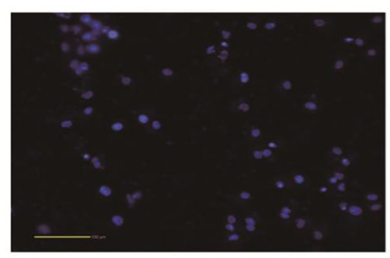

MIA

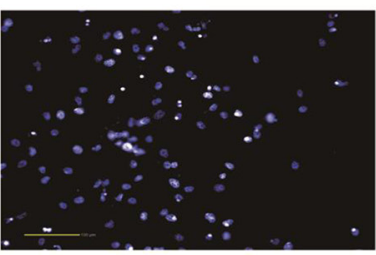

siMIA

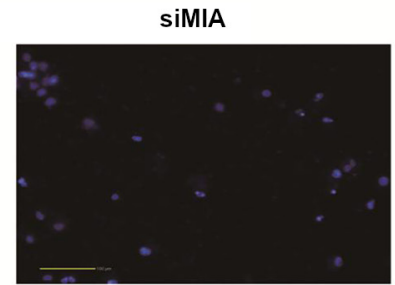

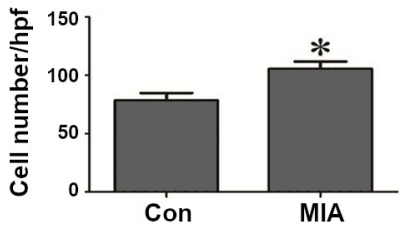
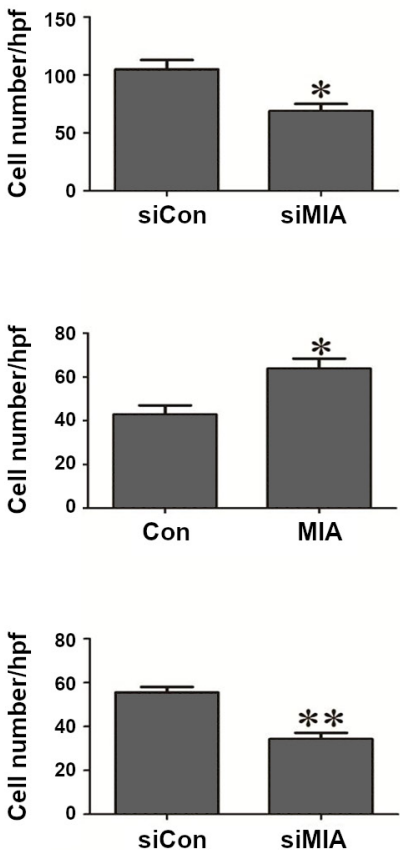

Figure 2. MIA was essential to migration and invasion of A549 cells. A) Overexpression of MIA suppressed the migration of A549 cells. B) Knockdown of MIA inhibited the migration of A549 cells. C) Overexpression of MIA suppressed the invasion of A549 cells. D) Knockdown of MIA inhibited the invasion of $\mathrm{A} 549$ cells. ${ }^{*} \mathrm{p}<0.05$ showed significant difference between two groups, $\mathrm{hpf}-\mathrm{high}$ power field

A

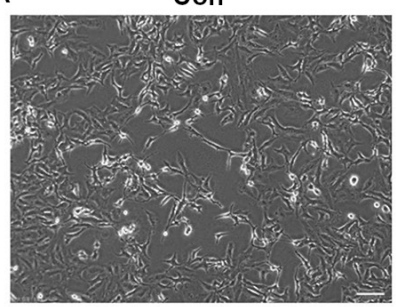

B

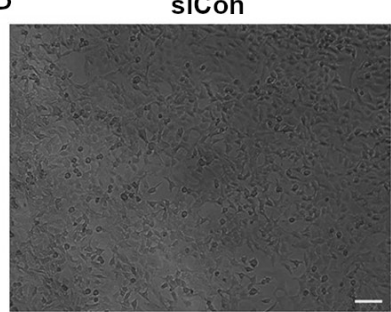

MIA

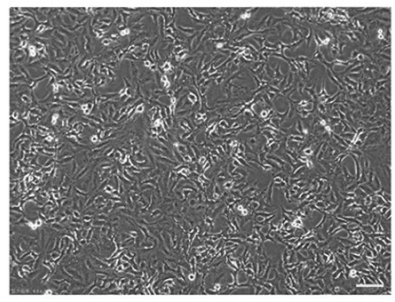

SIMIA

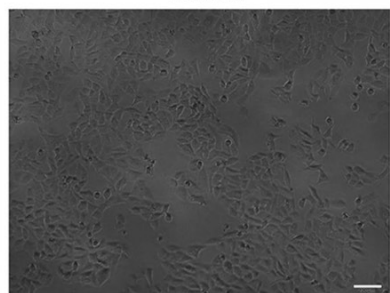

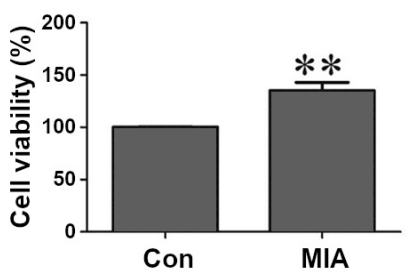

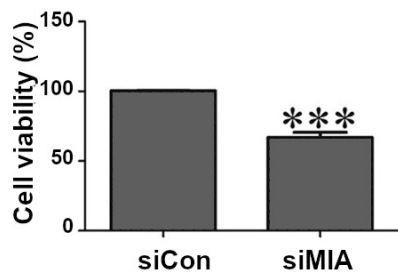

Figure 3. MIA regulated cell viability of A549 cells. A) Overexpression of MIA increased the viability of A549 cells. B) Knockdown of MIA decreased the viability of A549 cells. ${ }^{* *} \mathrm{p}<0.01$ or ${ }^{* * *} \mathrm{p}<0.001$ showed significant difference between two groups. 


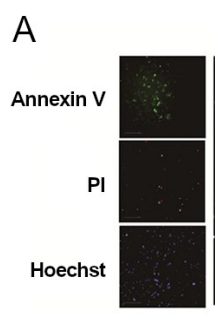

B

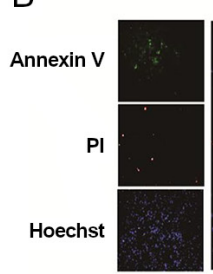

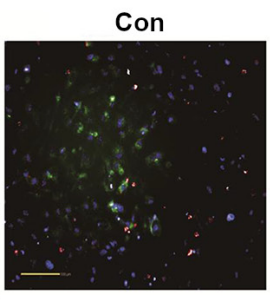

siCon

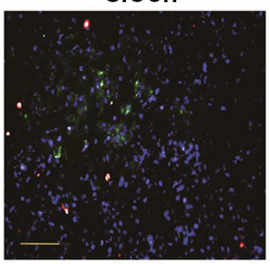

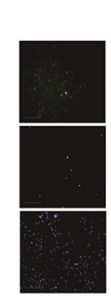

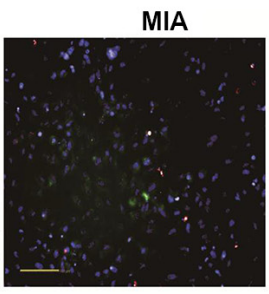

SIMIA
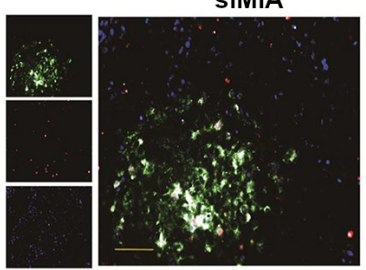
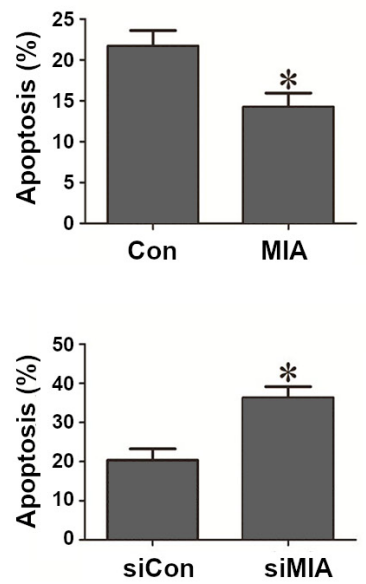

Figure 4. MIA regulated cell apoptosis in lung cancer. A) Overexpression of MIA in A549 cells suppressed cell apoptosis. B) Knockdown of MIA in A549 cells induced cell apoptosis. ${ }^{*} \mathrm{p}<0.05$ showed significant difference between two groups.

A

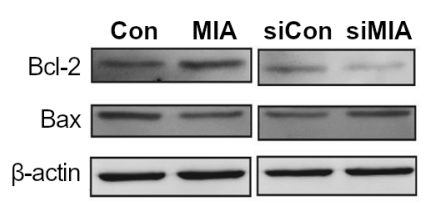

$\mathrm{D}$

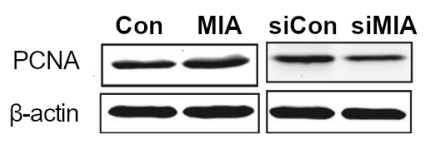

F

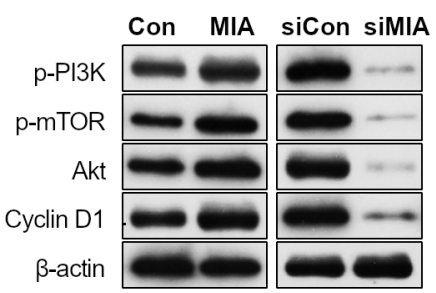

$B$

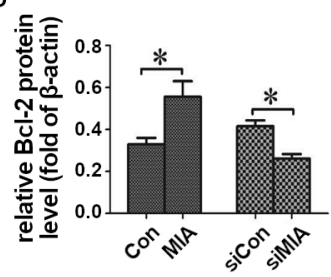

E

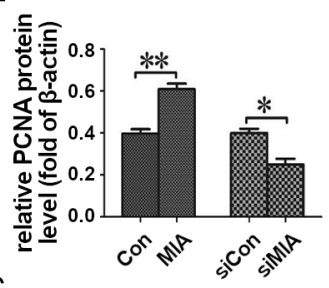

G

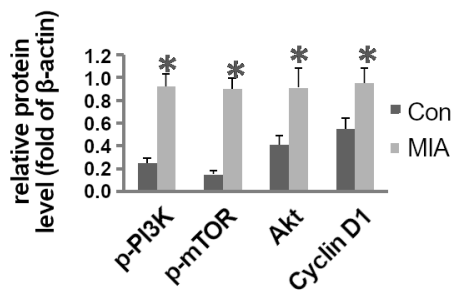

C

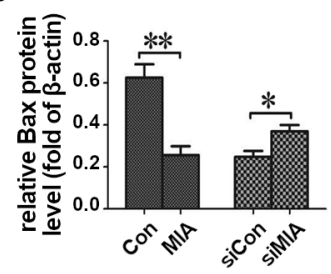

$\mathrm{H}$

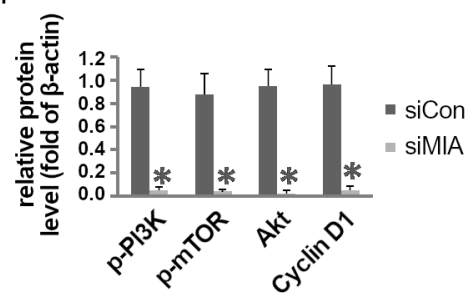

Figure 5. Western blotting analysis of downstream genes regulated by MIA. A, B and C) Bcl-2 was induced following MIA overexpression and decreased after MIA knockdown. Bax decreased with MIA overexpression but increased reversely after MIA knockdown in A549 cells. D and E) The level of PCNA was upregulated after MIA was increased in A549 cells but it was downregulated when MIA was knocked down. F, G and H) The expressions of Akt, Cyclin D1, phosphorylated PI3K, and phosphorylated mTOR were regulated by MIA. B, C, E, G and H) displayed the gray value of Bcl-2, Bax, PCNA, phosphorylated PI3K, phosphorylated mTOR, Akt, and Cyclin D1 in A), D) and F) respectively. ${ }^{\star} \mathrm{p}<0.05$ and ${ }^{\star *}$ p $<0.01$ showed significant difference between two groups.

underlying mechanism? As MIA suppressed cell apoptosis in lung cancer, we determined the expression pattern of typical apoptosis-related genes, such as Bax and Bcl-2. As shown in Figures 5A, 5B and 5C, Bcl-2 was increased when MIA was overexpressed in A549 cells. But it was declined greatly after the knockdown of MIA. Reversely, Bax was reduced when MIA was overexpressed. And it was increased following the knockdown of MIA. PCNA is a marker of cell proliferation. It was also increased in cells overexpressing MIA and declined after knockdown of MIA in lung cancer cells 
(Figures 5D, 5E). In addition, the expressions of phosphorylated PI3K, phosphorylated mTOR, Akt and Cyclin D1 were decreased when MIA was knocked down. But the expressions were increased when MIA was overexpressed in A549 cells (Figures 5F, 5G). PI3K/mTOR signaling is also a proliferation signaling pathway and abnormally activated in many types of tumors. Conclusively, MIA regulates the expression of apoptosis- and proliferation-related genes in lung cancer.

\section{Discussion}

Lung cancer is one of the most commonly seen leading causes of cancer-related deaths worldwide [1, 2]. The majority of lung cancer patients could not benefit much from traditional therapies, such as surgical removing or radiochemotherapy $[1,2]$. Heterogeneity could partially account for the poor prognosis in lung cancer patients [22]. To date, more than one molecule has been proved to play critical roles in lung cancer and some of them were considered as biomarkers for the diagnosis or therapy of lung cancer. For example, CEA was upregulated in lung cancer and was chosen as a biomarker for the diagnosis of lung cancer [23]. PD-1 is an inhibitory signal molecule against the immune system and a specific antibody targeting PD-1 was developed to treat lung cancer patients in recent years [24].

In this study, our data suggested MIA as a novel target for therapy of lung cancer. As stated above, MIA expression was positively associated with aggressive behaviors in lung cancer. The ability of migration, as well as invasiveness of A549 cells, was enhanced following MIA overexpression, and vice versa. This was consistent with the function of MIA in melanoma. MIA was reported to affect the attachment of melanoma cells to the extracellular matrix (ECM) followed by abnormal cell migration and invasion [7]. In pancreatic cancer, MIA also regulated cell migration and invasion [18]. But in previous reports, the cell proliferation was not influenced by MIA in cancer cells. However, the upregulated expression of MIA promoted proliferation in lung cancer cells A549 and vice versa. Known to us all, cancer is characterized by unlimited cell expansion and aggressiveness [25]. Therefore, it was rational to deduce that MIA contributes to the progression of lung cancer.

Besides, MIA was demonstrated to suppress the apoptosis of A549 cells. But the cell apoptosis rate was induced following knockdown of MIA. Evading from cell apoptosis is another hallmark in cancers [25]. And this is the first study showing that MIA regulated cell apoptosis in cancers. In other words, our data further supported the oncogenic function of MIA in the progression of lung cancer by regulating cell apoptosis. Apoptosis is a programmed cell death process and plays an important role in the development or homeostasis [26]. In nearly all types of cancers, apoptosis signaling is suppressed [26]. In this study, Bcl-2, an anti-apoptotic molecule, was increased when MIA was overexpressed in A549 cells. But the level of Bcl-2 was declined when MIA was knocked down. Bcl-2 is a crucial member of the $\mathrm{Bcl}-2$ protein family and affects the intrinsic apoptosis pathway by regulating the release of cytochrome c from mitochondria or by interacting with Bax through binding to Apaf-1 [27]. Bax is a pro-apoptotic molecule and promotes cell apoptosis by forming mitochondrial permeability transition pore followed by the release of cytochrome $c$ in many kinds of cancers [28]. Cells are destined to die once the cytochrome $\mathrm{c}$ is released. In this study, the expression of Bax was shown to be negatively correlated with the level of $\mathrm{Bcl}-2$ and MIA in lung cancer. In other words, a high level of MIA increased the expression of Bcl-2 but decreased Bax, which would lead to the release of cytochrome $c$ followed by cell apoptosis in lung cancer. PCNA is a known marker for cell proliferation and is associated with the prognosis of cancer patients [29]. PCNA was demonstrated to be altered positively with the expression of MIA in A549 cells. Meanwhile, proliferative molecules such as PI3K, mTOR, Akt and Cyclin D1 were all regulated by MIA. PI3K/mTOR is a typical signaling pathway regulating cell proliferation and often over-activated in cancers. Based on the above in vitro data and molecular expression profile, MIA was deduced to be an oncogene in lung cancer.

MIA was considered as a serum marker to monitor the metastatic melanoma [30]. Here, MIA was also shown to be expressed significantly higher in the peripheral blood of lung cancer patients compared to that in healthy persons. Furthermore, the concentration of MIA in lung cancer tissues was much higher than in the adjacent normal controls. This was consistent with a previous report by Sasahira. Sasahira et al. proved by immunohistochemistry that MIA was expressed much stronger in tissues from lung cancer patients and proposed MIA as a useful marker for lung cancer [31]. Thereof, the data in this study further supported the conclusion by Sasahira and suggested that MIA might also be used as a serum marker for the diagnosis of lung cancer in clinics.

In summary, MIA was proved to be a tumor oncogene and promoted tumorigenesis in lung cancer. Moreover, MIA was clinically overexpressed in lung cancer tissues and was released into the peripheral blood of lung cancer patients. This study provides us a novel candidate biomarker for the diagnosis or therapy of lung cancer patients.

Acknowledgements: This study is supported by National Natural Science Foundation of Zhejiang Province (No.Y16H160002).

\section{References}

[1] SIEGEL RL, MILLER KD, JEMAL A. Cancer Statistics, 2019. CA Cancer J Clin 2019; 69: 7-34. https://doi.org/10.3322/ caac. 21551

[2] SIEGEL RL, MILLER KD, JEMAL A. Cancer Statistics, 2018. CA Cancer J Clin 2018; 68: 7-30. https://doi.org/10.3322/ caac. 21442 
[3] DONG N, SHI L, WANG DC, CHEN C, WANG X. Role of epigenetics in lung cancer heterogeneity and clinical implication. Semin Cell Dev Biol 2017; 64: 18-25. https://doi. org/10.1016/j.semcdb.2016.08.029

[4] WANG DC, WANG X. Tomorrow's genome medicine in lung cancer. Semin Cancer Biol 2017; 42: 39-43. https://doi. org/10.1016/j.semcancer.2016.11.003

[5] TUTAR Y, ÖZGÜR A, TUTAR E, TUTAR L, PULliERO A et al. Regulation of oncogenic genes by MicroRNAs and pseudogenes in human lung cancer. Biomed Pharmacother 2016; 83: 1182-1190. https://doi.org/10.1016/j.biopha.2016.08.043

[6] BLESCH A, BOSSERHOFF AK, APFEL R, BEHL C, HESSDOERFER B et al. Cloning of a novel malignant melanomaderived growth-regulatory protein, MIA. Cancer Res 1994; 54: 5695-5701.

[7] HAU P, WISE P, BOSSERHOFF AK, BLESCH A, JACHIMCZAK $\mathrm{P}$ et al. Cloning and characterization of the expression pattern of a novel splice product MIA (Splice) of malignant melanoma-derived growth-inhibiting activity (MIAY CD-RAP). J Invest Dermatol 2002; 119: 562-569. https://doi. org/10.1046/j.1523-1747.2002.00501.x

[8] BOSSERHOFF AK, STOLL R, SLEEMAN JP, BATAILLE $\mathrm{F}$, BUETTNER $\mathrm{R}$ et al. Active detachment involves inhibition of cell-matrix contacts of malignant melanoma cells by secretion of melanoma inhibitory activity. Lab Invest 2003; 83: 1583-1594. https://doi.org/10.1097/01. lab.0000097191.12477.5d

[9] STAHLECKER J, GAUGER A, BOSSERHOFF A, BÜTTNER R, RING J et al. MIA as a reliable tumor marker in the serum of patients with malignant melanoma. Anticancer Res 2000; 20: 5041-5044.

[10] BAUER R, HUMPHRIES M, FÄSSLER R, WINKLMEIER A, CRAIG SE et al. Regulation of integrin activity by MIA. J Biol Chem 2006; 281: 11669-11677. https://doi.org/10.1074/ jbc.M511367200

[11] WINKLMEIER A, CONTRERAS-SHANNON V, ARNDT S, MELLE C, BOSSERHOFF AK. Cadherin-7 interacts with melanoma inhibitory activity protein and negatively modulates melanoma cell migration. Cancer Sci 2009; 100: 261268. https://doi.org/10.1111/j.1349-7006.2008.01048.x

[12] SCHMIDT J, RIECHERS A, STOLL R, AMANN T, FINK $\mathrm{F}$ et al. Targeting melanoma metastasis and immunosuppression with a new mode of melanoma inhibitory activity (MIA) protein inhibition. PLoS One 2012; 7: e37941. https:// doi.org/10.1371/journal.pone.0037941

[13] KOLANCZYK M, MAUTNER V, KOSSLER N, NGUYEN $\mathrm{R}, \mathrm{KÜHNISCH} \mathrm{J}$ et al. MIA is a potential biomarker for tumour load in neurofibromatosis type 1. BMC Medicine 2011; 9: 82. https://doi.org/10.1186/1741-7015-9-82

[14] SASAHIRA T, KIRITA T, OUE N, BHAWAL UK, YAMAMOTO K et al. High mobility group box-1-inducible melanoma inhibitory activity is associated with nodal metastasis and lymphangiogenesis in oral squamous cell carcinoma. Cancer Sci 2008; 99: 1806-1812. https://doi.org/10.1111/ j.1349-7006.2008.00894.x
[15] SASAHIRA T, KIRITA T, KURIHARA M, YAMAMOTO $\mathrm{K}$, BHAWAL UK et al. MIA-dependent angiogenesis and lymphangiogenesis are closely associated with progression, nodal metastasis and poor prognosis in tongue squamous cell carcinoma. Eur J Cancer 2010; 46: 2285-2294. https:// doi.org/10.1016/j.ejca.2010.04.027

[16] HAU P, RUEMMELE P, KUNZ-SCHUGHART LA, DOERFELT A, HIRSCHMANN B et al. Expression levels of melanoma inhibitory activity correlate with time to progression in patients with high-grade glioma. Oncol Rep 2004; 12 : 1355.

[17] WAGNER V, RUDI J, NÄHER H, STREMMEL W. Seropositivity for MIA and S100 in patients with gastrointestinal carcinomas. Medical Oncol 2000; 17: 35-38. https://doi. org/10.1007/bf02826214

[18] EL FITORI J, KLEEFF J, GIESE NA, GUWEIDHI A, BOSSERHOFF AK et al. Melanoma inhibitory activity (MIA) increases the invasiveness of pancreatic cancer cells. Cancer Cell Int 2005; 5: 3. https://doi.org/10.1186/14752867-5-3

[19] QIN LX, TANG ZY. The prognostic molecular markers in hepatocellular carcinoma. World J Gastroenterol 2002; 8: 385-392. https://doi.org/10.3748/wjg.v8.i3.385

[20] THEAN LF, WONG YH, LO M, LOI C, CHEW MH et al. Chromosome 19q13 disruption alters expressions of CYP2A7, MIA and MIA-RAB4B lncRNA and contributes to FAP-like phenotype in APC mutation-negative familial colorectal cancer patients. PLoS ONE 2017; 12: e0173772. https://doi.org/10.1371/journal.pone.0173772

[21] IVANOV SV, PANACCIONE A, NONAKA D, PRASAD ML, BOYD KL et al. Diagnostic SOX10 gene signatures in salivary adenoid cystic and breast basal-like carcinomas. British J Cancer 2013; 109: 444-451. https://doi.org/10.1038/ bjc. 2013.326

[22] DONG ZY, ZHAI HR, HOU QY, SU J, LIU SY et al. Mixed responses to systemic therapy revealed potential genetic heterogeneity and poor survival in patients with non-small cell lung cancer. Oncologist 2017; 22: 61-69. https://doi. org/10.1634/theoncologist.2016-0150

[23] ZHAO W, YU H, HAN Z, GAO N, XUE J et al. Clinical significance of joint detection of serum CEA, SCCA, and bFGF in the diagnosis of lung cancer. Int J Clin Exp Pathol 2015; 8: 9506-9511.

[24] SHIEN K, PAPADIMITRAKOPOULOU VA, WISTUBA II. Predictive biomarkers of response to PD-1/PD-L1 immune checkpoint inhibitors in non-small cell lung cancer. Lung Cancer 2016; 99: 79-87. https://doi.org/10.1016/j.lungcan.2016.06.016

[25] HANAHAN D, WEINBERG RA. Hallmarks of cancer: The next generation. Cell 2011; 144: 646-674. https://doi. org/10.1016/j.cell.2011.02.013

[26] STRASSER A, CORY S, ADAMS JM. Deciphering the rules of programmed cell death to improve therapy of cancer and other diseases. EMBO J 2011; 30: 3667-3683. https://doi. org/10.1038/emboj.2011.307 
[27] LUANPITPONG S, CHANVORACHOTE P, STEHLIK C, TSE W, CALLERY PS et al. Regulation of apoptosis by Bcl-2 cysteine oxidation in human lung epithelial cells. Mol Biol Cell 2013; 24: 858-869. https://doi.org/10.1091/mbc.E12-10-0747

[28] WEI MC, ZONG WX, CHENG EH, LINDSTEN T, PANOUTSAKOPOULOU V et al. Proapoptotic BAX and BAK: a requisite gateway to mitochondrial dysfunction and death. Science 2001; 292: 727-730. https://doi.org/10.1126/science. 1059108

[29] LV Q, ZHANG J, YI Y, HUANG Y, WANG Y et al. Proliferating cell nuclear antigen has an association with prognosis and risks factors of cancer patients: a systematic review. Mol Neurobiol 2016; 53: 6209-6217. https://doi.org/10.1007/ s12035-015-9525-3
[30] USLU U, SCHLIEP S, SCHLIEP K, ERDMANN M, KOCH $\mathrm{HU}$ et al. Comparison of the serum tumor markers $\mathrm{S} 100$ and melanoma-inhibitory activity (MIA) in the monitoring of patients with metastatic melanoma receiving vaccination immunotherapy with dendritic cells. Anticancer Res 2017; 37: 5033-5037. https://doi.org/10.21873/anticanres.11918

[31] SASAHIRA T, KIRITA T, NISHIGUCHI Y, KURIHARA M, NAKASHIMA $\mathrm{C}$ et al. A comprehensive expression analysis of the MIA gene family in malignancies: MIA gene family members are novel, useful markers of esophageal, lung, and cervical squamous cell carcinoma. Oncotarget 2016; 7: 31137-31152. https://doi.org/10.18632/oncotarget.9082 